\title{
EDUCAÇÃO DO CAMPO E POLÍTICAS PÚBLICAS RECONHECER COMO DIFERENTE PARA AGIR DIFERENCIADAMENTE
}

\author{
FIELD OF EDUCATION AND PUBLIC POLITICAL: HOW TO RECOGNIZE DIFFERENT TO \\ ACT DIFFERENTIATEDLY
}

Wilson Schmidt**

Doutor em Etudes des sociétés latino-américaines, Université Sorbonne Nouve | França E-mail: wilson@ced.ufsc.br

REVISTA PEDAGÓGICA

Revista do Programa de Pós-graduação em Educação da Unochapecó | ISSN 1984-1566

Universidade Comunitária da Região de Chapecó | Chapecó-SC, Brasil Como referenciar este artigo: MUNARIN, A. SCHMIDT, W. Educação do Campo e Políticas Públicas: reconhecer como diferente para agir diferenciadamente. Revista Pedagógica, Chapecó, v.15, n.31, p. 21-43, jul./dez. 2013.

\begin{abstract}
RESUMO: Este texto é baseado em uma análise crítica dos dados fornecidos pelo Instituto Brasileiro de Geografia e Estatísticas (IBGE) e Instituto Nacional de Estudos e Pesquisas Educacionais Anísio Teixeira Página Inicial (INEP) sobre Santa Catarina. Ele indica que discutir os critérios utilizados para delimitar as áreas rural e urbana contribui para argumentos políticos a favor do fortalecimento da Educação no Campo. Se o campo for considerado numa perspectiva mais ampla do que a oficial existente, há uma rede significativa de escolas nele situadas. Elas não são vistas, contudo, como do campo, nem pelos professores, nem por dirigentes municipais de educação, nem pelas famílias dos educandos e, muitas vezes, nem mesmo pelos sujeitos coletivos que sustentam o Movimento de Educação do Campo. O reconhecimento e a visibilidade dessas escolas como escolas do campo constituem um primeiro e indispensável passo para que elas construam suas identidades de "escolas do campo" e funcionem como tal nos contextos de territórios rurais em que se inserem, protagonizando dinâmicas de desenvolvimento desses territórios em perspectiva de disputa de hegemonia.
\end{abstract}

PALAVRAS-CHAVE: Educação do Campo. Educação não-formal. Delimitação rural-urbano. Santa Catarina. Argentina.
ABSTRACT: This text is based on a critical analysis of data provided by IBGE (Brazilian Institute of Geography and Statistics) and INEP (National Institute of Educational Studies and Research Anísio Teixeira) about Santa Catarina. It indicates that discussing the criteria used to delimitate Rural and Urban areas contributes to political arguments in favor of strengthening $\mathrm{Ru}-$ ral Education. If we assume a broader perspective for the concept of Rural than the official one, we can say that there is a significant network of schools located in rural areas. Nevertheless, these schools are not recognized as Rural by teachers, by local education governments' leaders, by the students' families, and often not even by the institutions or groups that support Rural Education movements. The recognition and visibility of these schools as Rural Schools consist in a first and necessary step in order to consolidate their identities as "Rural Schools" and their operation as such in the context of the rural territories, leading development dynamics in those territories as opposed to external hegemonies.

KEYWORDS: Rural education. Non formal education. Rural-urban delimitation. Santa Catarina. Argentina. 
* Doutor em Educação pela Pontifícia Universidade Católica de São Paulo (PUC/SP). Professor e pesquisador da Universidade $\mathrm{Fe}$ deral de Santa Catarina. Pós-doutorado no Programa de Pós-Graduação em Geografia da UNESP - Campus Presidente Prudente. E-mail: munarim@ced.ufsc.br

** Doutor em Etudes des sociétés latino-américaines, Université Sorbonne Nouve. Professor e pesquisador da Universidade Federal de Santa Catarina. E-mail: wilson@ ced.ufsc.br
- Mas entendo que toda a gente devia ser capaz de separar o trigo do joio. O que é mau, de um lado; o que é bom, do outro. [...]

- Não pode ser. O mal e o bem, o bom e o mau, andam sempre misturados. Nunca se é completamente bom ou completamente mau. [...]

- Se toda a gente pensasse como tu, ninguém se entendia. É preciso regras, é preciso leis!

- E quem as fez? E quando? E com que fim? [...] E, afinal, pensas com as tuas ideias ou com as regras e as leis que não fizeste?...

(José Saramago, em Claraboia).

\section{INTRODUÇÃO}

Há quinze anos, a primeira Conferência Nacional "Por uma Educação Básica do Campo" apontou, entre vários desafios e propostas de ação, a necessidade de "montar uma agenda e uma rede de pesquisa que recoloque o campo como objeto de preocupação de estudiosos", assim como, "envolver as universidades no debate quanto à inclusão de linhas de pesquisa, atividades de extensão e de ensino a respeito do campo" (Unesco, 1998a, p. 4). Passado esse período, a noção de campo permanece gerando debates e controvérsias entre estudiosos (e militantes) da Educação do Campo.

É sabido que a opção pelo adjetivo "campo" e o substantivo "educação" (acompanhado da preposição "do") foi feita, naquela oportunidade, para marcar uma clara ruptura com a concepção e a prática de educação rural no Brasil. Nesse quadro, seja qual for o conceito de Educação Não-Formal que possa ser adotado, entende-se que ele englobaria - ou deveria englobar - o entendimento subjacente ao texto: na perspectiva da Educação do Campo, "escola do campo não é só escola". Ou seja, "sendo capaz de protagonizar processos de desenvolvimento", a escola do campo deve ser entendida também como uma instituição ou espaço de ação flexível do ponto de vista do método e das práticas pedagógicas.

A opção pelo adjetivo "campo", por sua vez, resultou do fato do Movimento Nacional de Educação do Campo ter sua origem em movimentos sociais (Anhaia, 2010) que buscavam incluir, "no processo" da citada Conferência, uma "reflexão sobre o sentido do trabalho camponês e das lutas sociais e culturais dos grupos que vivem e tentam garantir a sobrevivência desse trabalho" (Unesco 1998b, p. 9). Assim, mesmo considerando que "educação do campo" se volta "ao conjunto dos trabalhadores e trabalhadoras do campo", a opção política foi, sobretudo, de "resgatar o conceito de camponês ${ }^{1}$ (Unesco, 1998b, p. 9). "Campo" era associado, dessa forma, a camponês. Ressalta-se que, com o tempo, não é esta noção - pelo menos ainda não - a que prevalecerá, mas a expressão "povos do campo".
1 A Educação do Campo não existe sem a agricultura camponesa, porque foi criada pelos sujeitos que a executam" (Fernandes; Molina, 2004). 
Ao longo de um decênio e meio, quando os autores que trabalham nessa perspectiva procuraram mostrar seja que o campo não está "em extinção", seja a relevância dele para a sociedade brasileira, precisaram considerar uma delimitação e uma quantificação do que seja esse campo. Com isso, eles necessitaram passar à arena dos conceitos operacionais. Apesar de levarem em conta ponderações de diversos analistas, acabaram utilizando os dados de situação ou localização de domicílios adotados pelo Instituto Brasileiro de Geografia e Estatística (IBGE) (ver, por exemplo, Fernandes, 1999; Molina, 2003).

O IBGE trabalha, nesses casos, com os limites "administrativos" entre rural e urbano, fixados pelos legislativos municipais. O "rural" resultante é, em geral, produto de objetivos fiscais e termina sendo, simplesmente, o que "não é urbano" ou o que "sobra". Não são levados em conta, efetivamente, os aspectos geográficos, sociais, econômicos ou culturais; justamente os que interessam na perspectiva de evidenciar, dentro do global, as particularidades do campo e de seus povos.

Não é demais recordar que a declaração final da II Conferência Nacional por uma Educação do Campo (CNCE, 2004, grifo nosso) defendeu "a mudança da forma arbitrária atual de classificação da população e dos municípios como urbanos e rurais; ela dá uma falsa visão do significado da população do campo em nosso país, e tem servido como justificativa para a ausência de políticas públicas destinadas a ela”.

Proposições de aprofundamentos no trabalho com essa delimitação têm sido, contudo, tomadas negativamente por uma parcela significativa daqueles que compõem o Movimento de Educação do Campo. Duas são as razões aparentes: a primeira é que, conjetura-se, o debate seria levado para possíveis chicanas técnicas, ao invés de manter-se "no límpido ambiente da política e dos interesses de classe"; a segunda é que o esforço da delimitação, supostamente, favoreceria uma visão dualista entre campo e cidade; ou entre urbano e rural. Visão dualista que, por sua vez, também contribuiria para "encobrir as contradições fundamentais de nossa sociedade".

Para evitar tal ocultação, foram incorporadas ao debate, por Bernardo Mançano Fernandes e seus orientados em cursos de pós-graduação, sempre na perspectiva de "estudar a sociedade a partir da luta de classes" (Felício, 2010), as noções de território imaterial do campesinato ou de movimentos socioterritoriais ligados ao campesinato. Um questionamento de base é feito, por esses autores, à noção de território na forma como passou a ser mobilizada em ações públicas governamentais e não governamentais voltadas ao desenvolvimento. Considerando que o conceito de território passou, com isso, a ser tão disputado quanto os próprios territórios, Fernandes (2008, p. 3) julga insufi- 
ciente a compreensão do território "apenas como espaço de governança", ou "como conceito central na implantação de políticas públicas e privadas, nos campos, nas cidades e nas florestas, promovidas pelas transnacionais, governos e movimentos socioterritoriais". Ao analisar "o campo da Educação do Campo", Fernandes e Molina (2004) definem o território como "espaço político por excelência, campo de ação e de poder, onde se realizam determinadas relações sociais”. Para os autores citados, "o conceito de território é fundamental para compreender os enfrentamentos entre a agricultura camponesa e o agronegócio, já que ambos projetam distintos territórios" (Fernandes; Molina, 2004, p. 1).

Sem negar a importância dessa perspectiva teórica como base de sustentação do Movimento de Educação do Campo, ou seja, como base da luta social, a perspectiva deste texto é diferente. A preocupação deste trabalho, em primeiro lugar, é justamente com a governança, entendida como arranjos institucionais inéditos que façam com que os governos locais tomem decisões capazes de influenciar os destinos das comunidades rurais (Jean, 2010), mais especificamente com a efetivação de políticas públicas voltadas a uma educação universal nos "territórios rurais", respeitando, ao mesmo tempo, as identidades dos seus habitantes, sem urbanocentrismo e sem ruralismo (Munarim, 2010). Para isso, nossa intenção é associar campo à noção-chave "territórios rurais". Para ser coerente com a abordagem assumida neste texto, adota-se uma definição conceitual operativa de território rural. Trata-se de uma "unidade de gestão que permite integrar uma realidade econômica multissetorial e dimensões políticas, sociais, culturais e ambientais que vêm construindo uma institucionalidade dinâmica, ainda que complexa" (Peric; Ribeiro, 2005, p. 25). Perico e Ribeiro (2005, p. 26) destacam, ainda, que um território rural pode conter centros urbanos maiores, "cuja existência e funcionalidade territorial ou regional estão definidas pelas atividades de uso dos recursos naturais sobre os quais se localiza”.

No âmbito da intervenção governamental voltada ao desenvolvimento rural, é importante lembrar a perspectiva apontada pelo Ministério do Desenvolvimento Agrário, que entende a elaboração, a gestão e a decisão das políticas como

[...] a ação que parte do reconhecimento do território como projeção e expressão de uma população com grupos sociais relativamente distintos, que se relacionam interna e externamente por meio de processos específicos, onde se pode distinguir um ou mais elementos que indicam identidade e coesão social, cultural e territorial. (Brasil, 2004, p. 4).

Este texto, portanto, propõe indicar, a partir de um trabalho crítico sobre os dados do IBGE e do Instituto Na- 
cional de Estudos e Pesquisas Educacionais Anísio Teixeira (INEP), para Santa Catarina: 1) que o trabalho técnico contribui para os argumentos políticos favoráveis ao fortalecimento da Educação do Campo de uma forma mais ampla; 2) que o debate sobre a delimitação de rural e urbano aponta para uma visão sinérgica entre o que é considerado, hoje, um e outro (ou, de forma mais clara, para a definição de "campo"); 3) que, na liça da governança ou das políticas públicas, há de se considerar a existência de ampla diversidade de contextos rurais.

Além da introdução e das considerações finais, este artigo está estruturado em três partes. Inicialmente, procura-se apresentar as questões relacionadas à delimitação de urbano e rural no Brasil e as implicações sobre a forma como é percebida e registrada a localização das escolas. Em seguida, busca-se ilustrar o que se considera um subdimensionamento das escolas do campo em Santa Catarina, mostrando que essa perspectiva se associa a uma visão de carência de infraestrutura. Reafirma-se que a revisão da delimitação do que é rural e urbano - para definir a localização da população e das escolas - pode contribuir para que as escolas situadas no campo levem efetivamente em conta as necessidades, particularidades e potencialidades das populações do campo; nesse caso, tomamos a escola como instrumento potencialmente capaz de protagonizar processos determinados de desenvolvimento. Na terceira parte, finalmente, a experiência nacional da Argentina é evidenciada como uma alternativa nacional àquela seguida no Brasil no que se refere ao entendimento e classificação de "escola rural".

\section{EDUCAÇÃO, LOCALIZAÇÃO DA ESCOLA, UR- BANA OU RURAL... E O CAMPO?}

As informações sobre a "localização" ou "zona" da escola são preenchidas pelos dirigentes do estabelecimento de ensino, quando não vêm já "bloqueadas" no formulário informatizado para preenchimento do Censo Escolar. No caderno de instruções para o preenchimento do questionário pelas unidades escolares, o INEP recomenda que "se anote a demarcação definida pelo IBGE para a zona em que se situa a escola". Ou seja, que se assinale "urbana", para aquelas escolas situadas dentro do perímetro urbano ou nas sedes dos distritos do município; e "rural", para aquelas que estão fora dessas zonas. A abordagem administrativa (Abramovay, 2000) posta em prática pelo IBGE, por si só torna inconsistente esse recorte. Como destacam Favareto e Abramovay (2010, p. 51), "o problema maior da maneira como áreas urbanas e rurais são definidas pelo IBGE reside no fato de que cada município estabelece os limites entre elas de acordo com diferentes critérios". Isso, além de dificultar comparações entre municípios e territórios, desconsidera o que é fundamental: "traços geográficos típicos da ruralidade". 
2 Os "critérios de corte" por patamar populacional variam bastante no mundo. Abramovay (2000, p. 5) destaca o limite de 20 mil habitantes, por ser "parâmetro frequente em organizações internacionais e proposto pelo sociólogo francês Henri Mendras". Para Verde (2004, p. 11), "pode-se dizer que há um certo entendimento entre pesquisadores em considerar rurais os municípios com menos de 20 mil habitantes". Veiga (2004, p. 78), por sua vez, trata esse corte como uma "convenção, que vem sendo usada desde os anos 1950". Os três autores destacam, logo em seguida, os limites desse critério e a necessidade de considerar a densidade demográfica. Apesar disso, mantivemos esse corte: primeiro pela vantagem de sua simplicidade operacional e para permitir uma comparação com o critério administrativo adotado pelo IBGE e pelo INEP, julgado ainda mais inadequado pelos mesmos autores; segundo, porque havia sinais de que, parafraseando Verde (2004), para o caso do Paraná, "essa medida [seria] mais aderente à realidade rural" catarinense. Veiga (2002) buscou, através de testes estatísticos, calibrar "a dose" certa para o Brasil na combinação entre patamar populacional e densidade demográfica. $\mathrm{O}$ autor concluiu que é possível considerar rural (ou de pequeno porte) os municípios que têm simultaneamente menos de 50 mil habitantes e menos de 80 habitantes por quilometro quadrado (o que equivale a 100 hectares). Urbanos (ou de grande porte) são considerados os municípios com mais de 100 mil habitantes. São considerados de médio porte ou "ambivalentes" aqueles municípios que possuem entre 50 e 100 mil habitantes ou os que, mesmo tendo uma população inferior a 50 mil habitantes, apresentam uma densidade demográfica superior a $80 \mathrm{hab} . / \mathrm{km}^{2}$.
Seguindo uma linha de trabalhos que se inicia com uma classificação utilizada internacionalmente pela Organização para a Cooperação e Desenvolvimento Econômico (OCDE), em 1994, autores brasileiros como Abramovay (2000), Veiga (2002, 2004) e Verde (2004) têm apontado, na delimitação de rural e urbano, para a necessidade de combinar critérios estruturais e funcionais, envolvendo, no mínimo, o tamanho da população do município, sua densidade demográfica e sua localização em relação a aglomerações urbanas. Pode-se, dessa forma, construir a ideia de regiões predominantemente ou essencialmente rurais (ou "territórios rurais") e, a partir dela, pensar de forma mais clara e territorial sobre os dados da Educação do Campo.

Municípios com até vinte ou cinquenta mil habitantes (nesse caso, combinado com densidade demográfica inferior a oitenta habitantes por quilômetro quadrado) são considerados pelos autores citados como rurais ${ }^{2}$. Destaca-se que os autores citados julgam que "não têm sentido perímetros ou zonas internos aos municípios" e que é "anacrônica e aberrante a fronteira inframunicipal entre o rural e o urbano", o que é exatamente o critério utilizado pelo IBGE e adotado pelo INEP.

Ao analisar especificamente o Estado de Santa Catarina, pode-se ter uma ideia mais clara do que essa mudança de olhar significa. No caso catarinense, segundo dados do Censo Demográfico de 2010 (que é realizado pelo IBGE e segue os critérios administrativos supramencionados), $84 \%$ da população é urbana e o $16 \%$ restante é rural. Pode-se considerar, a partir dessa porcentagem, que o estado possui alta taxa de urbanização e que, portanto, não faz mais sentido pensar em uma estratégia política, em longo prazo, centrada na Educação do Campo. Essa concepção é reforçada quando se considera a tendência de diminuição da população rural, já que, em 2000, seguindo os mesmos critérios, ela representava $21 \%$. Ou seja, em apenas uma década, tal participação reduziu-se em $5 \%$, ou um quarto.

Se seguirmos, contudo, o critério de corte mencionado por Abramovay (2000) e Verde (2004), vamos constatar que 232 dos 293 municípios catarinenses (80\%) têm população inferior ao patamar de vinte mil habitantes e devem ser considerados, por isso, como municípios rurais em sua totalidade (mapa 1). O somatório de suas populações é de 1,63 milhões de habitantes, o que corresponde a $26 \%$. Nessa perspectiva, o "território rural" catarinense ocuparia quatro quintos da área do estado e nela viveriam e trabalhariam mais de um quarto da população do estado. No que interessa mais diretamente a este artigo, deveríamos considerar, a partir daí, como "rurais" ou "no campo" todas as escolas situadas nesses duzentos e trinta e dois municípios. 
3 O critério de definir como urbano um município que pertence a uma região metropolitana, proposto por Veiga (2002), não pode ser aplicado em Santa Catarina. Afinal, no estado são nove as regiões metropolitanas, cobrindo boa parcela do território. Elas foram criadas, entre 1998 e 2002, "para integrar o planejamento e a execução de funções públicas de interesse comum" (Diário Catarinense, 1 de agosto de 2011. Disponível em: <http://www.clicrbs.com.br/diariocatarinense $/$ jsp/default2.jsp?uf=2\&local=18\&sou rce $=$ a3425840.xml\&templat $=3898$.dwt\&ed ition $=17648 \&$ section $=213>$.). Com a reforma administrativa, em 2007, no governo de Luiz Henrique da Silveira, elas foram extintas, pois foram consideradas desnecessárias depois da criação das secretarias de desenvolvimento regional. Em 2010, contudo, as instituições foram restabelecidas com a lei complementar 495, com o objetivo principal "de facilitar a busca de financiamentos federais destinados exclusivamente a esses grupos" (Ibidem, grifo nosso). Além da não efetiva implementação das regiões metropolitanas, fica claro no debate sobre elas que, mais uma vez, não foram aspectos geográficos, sociais, econômicos ou culturais que foram levados em conta.
Mapa 1 - Tipologia dos municípios catarinenses seguindo corte de 20 mil habitantes e os dados do Censo Demográfico 2010 (IBGE)

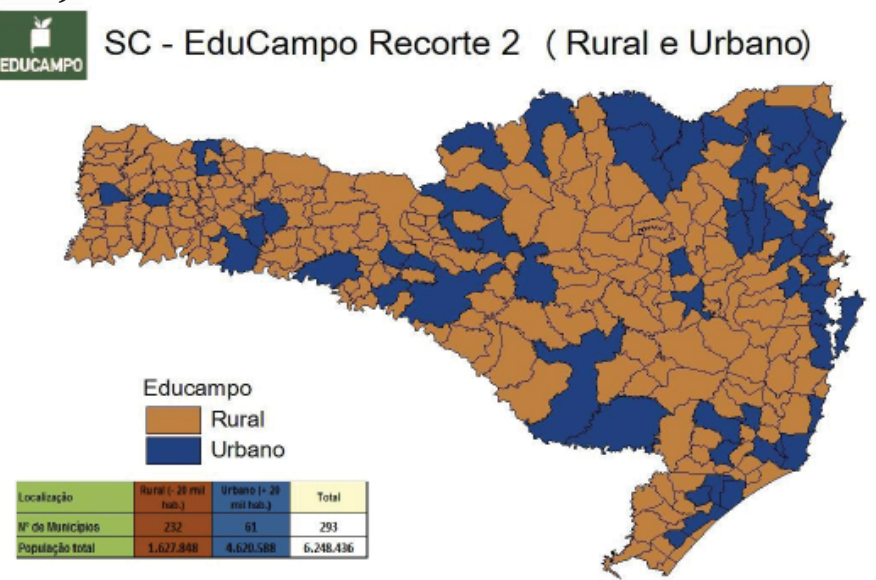

Ao adotarmos os criterios propostos por veiga (2002) ${ }^{3}$, constatamos que 228 municípios (78\%) são "essencialmente rurais" e 53 são considerados "ambivalentes" (18\%). Nos municípios essencialmente rurais, vivem 1,73 milhões de habitantes, ou $28 \%$ da população total catarinense. Se forem adicionados os 1,85 milhões que vivem nos municípios ambivalentes (29,6\%), pode-se afirmar que mais da metade da população catarinense não é urbana (mapa 2). Novamente, voltando ao que é central neste artigo, deveriam ser consideradas urbanas apenas aquelas escolas situadas nos doze municípios urbanos.

Mapa 2 - Tipologia dos municípios catarinenses seguindo os critérios propostos por Veiga (2002) e os dados do Censo Demográfico de 2010 (IBGE)

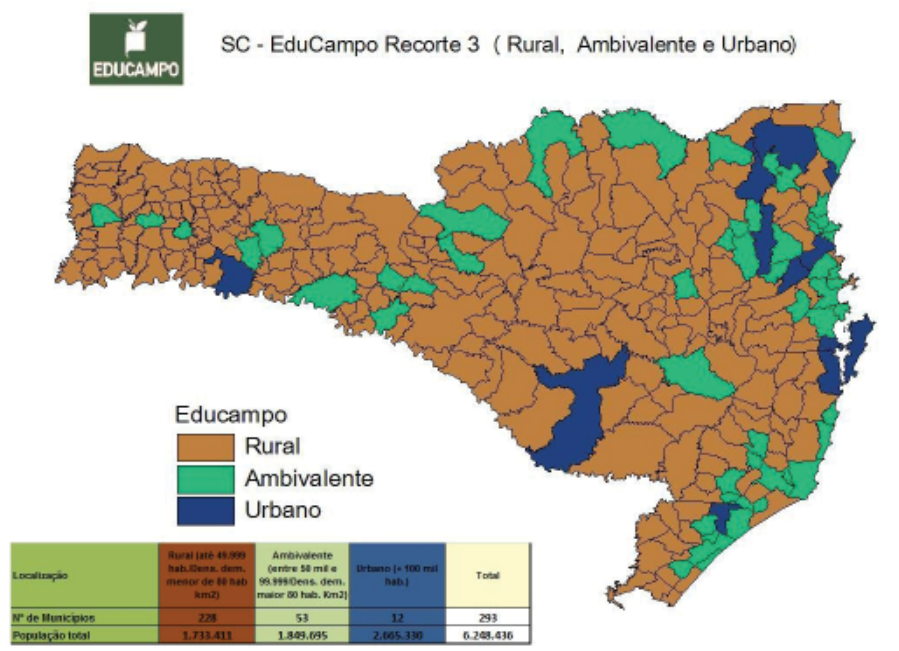

A visualização desses mapas em trabalhos de formação e reflexão realizados pelo Instituto de Educação do Campo da Universidade Federal de Santa Catarina (UFSC) tem impactado Dirigentes Municipais de Educação (DME) e contribuído para um reposicionamento deles - ou, pelo menos, para uma maior abertura, para (re)pensar a pos- 
tura das secretarias municipais de educação em relação à forma como entendem a "escola do campo". Essa abordagem permite, também, por parte dos DME, uma melhor compreensão da definição de escola do campo presente no Decreto da Educação do Campo (Brasil, 2010). Recorde-se que, para o referido Decreto, escola do campo não é somente aquela "situada em área rural, conforme definida pela Fundação Instituto Brasileiro de Geografia e Estatística - IBGE" (Brasil, 2010), mas, também, aquela "situada em área urbana, desde que atenda predominantemente a populações do campo" (Brasil, 2010). Portanto, implicitamente o documento legal aponta para a noção de município predominantemente ou essencialmente rural.

Nesse contexto, apresenta-se mais um importante desafio: a superação de um viés setorial na percepção do rural, que, apesar de tudo, persiste em parte do Movimento Nacional de Educação do Campo. Em outras palavras, associa-se o rural à agricultura e os problemas do campo, centralmente, à questão fundiária. Essa visão contraditória persiste, inclusive, em obras de autores que trabalham com a noção de totalidade e com a "não oposição" ou "não antagonismo" entre campo e cidade e, por consequência, entre educação do campo e educação da cidade. O centralismo que tomou, dentro do Movimento Nacional de Educação do Campo, a questão da propriedade ou posse e uso da terra dificulta a percepção de que um novo projeto de desenvolvimento para o campo brasileiro precisa extrapolar a ótica setorial. A longa transição demográfica vivida pelo campo brasileiro exige para mantê-lo a curto e médio prazo, "com gente" e "com vida", uma ótica eminentemente territorial e, com ela, os parâmetros de intervenção precisam ser ampliados para o aumento do emprego e da renda, inclusive e principalmente fora da agricultura (Abramovay, 2007).

Aplicada a Santa Catarina, essa abordagem não permitirá - é certo - apontar claramente as desigualdades existentes no campo catarinense e, ainda menos, mapear e quantificar, no estado, os diferentes campos apontados por Fernandes e Molina (2004) - "do agronegócio", do "pequeno agricultor", "dos sem-terra". Ainda mais, considerando a interpenetração deles na complexa composição do mundo agrário e agrícola de Santa Catarina. Não se conhece, inclusive, pelo menos até agora, qualquer pista clara para a consecução desse objetivo, em uma visão macro ou meso (o que nos interessa, no momento, um estado da federação).

Seria obviamente redutor, por exemplo, considerar como "o campo da Educação do Campo" catarinense os 156 projetos de assentamento de reforma agrária, listados pelo Instituto Nacional de Colonização e Reforma Agrária (INCRA) em Santa Catarina, que totalizam 5.890 famílias e ocupam uma área, descontínua e dispersa, de cento e um mil hectares, equivalente a $1 \%$ da área do estado (INCRA, 2011). Redutor, também, seria reputar os 168.544 estabe- 
4 Conforme Lei 11.326, a qual "estabelece os conceitos, princípios e instrumentos destinados à formulação das políticas públicas direcionadas à Agricultura Familiar e Empreendimentos Familiares Rurais" (Brasil, 2006). lecimentos agropecuários da agricultura familiar ${ }^{4}$ como "o campo da Educação do Campo" catarinense (IBGE, 2009). Nesse caso, sendo também descontínua, sua área equivaleria a 2,7 milhões de hectares, ou $28 \%$ da total do estado, e congregaria em torno de $12 \%$ da população.

Ressalta-se que em trabalhos com dirigentes municipais de educação é possível perceber que eles fazem essa mesma associação direta entre campo e agricultura. Além disso, o campo é associado ao "interior" dos municípios e à falta de infraestrutura. Dessa forma, persiste-se em um entendimento do rural - ou, como é mais frequente, do "interior" (por menor que seja o município do DME) - como símbolo do atraso, que não tem mais tanta importância na dinâmica das municipalidades brasileiras. O que em geral se ouve é mais coloquial, como: "o meio rural vai se acabar". O contraponto resume-se à visões românticas, que registram e perpetuam memórias de um passado supostamente idílico, harmônico, sem conflitos e sem resistências.

É nesse quadro que vai se trabalhar, efetivamente, a perspectiva e os desafios da Educação do Campo. Isso não será possível sem um novo olhar sobre o "mundo rural" que considere as transformações socioeconômicas e culturais pela qual passa o cenário rural brasileiro. A escola do campo precisará considerar essas transformações se deseja ser transformadora: há de se pensar em um (re)posicionamento de seus objetivos, em função dos interesses daquelas (e das competências necessárias àquelas) pessoas que desejam permanecer, viver e trabalhar no campo.

Não se trata absolutamente de pensar no velho e superado mote da "fixação". Trata-se de considerar que cada vez mais pessoas que vivem no campo (inclusive jovens) não se ocupam - e não querem se ocupar - profissionalmente com atividades agropecuárias. Dizendo de outra forma, o peso da agropecuária na formação da renda e na ocupação dos membros das famílias do campo, se continua importante, é cada vez menor. No campo, existem estabelecimentos comerciais, industriais, atividades de turismo, hospitais, casas de saúde e repouso, enfim, um número de atividades que não cessam em se expandir. É claro que o ritmo do declínio da agricultura pode variar em função de inúmeras circunstâncias. O desafio, então, está em formular projetos que resultem em dinâmicas locais virtuosas capazes de propiciar a elevação no nível de renda dos mais pobres e a utilização sustentável dos recursos naturais (Abramovay, 2007). São essas novas dinâmicas, inclusive, que aumentarão a atratividade desses municípios para os jovens que neles habitam. Por isso, é importante voltar à noção de territórios rurais (ou de municípios rurais), para, novamente, questionar a atual classificação de escola rural estabelecida pelo INEP, apontando para a pertinência do entendimento de escola do campo do Decreto da Educação do Campo (BRASIL, 2010). Isso ajuda a superar a visão de 
5 Optou-se por relacionar apenas os menores de dois mil para estabelecer um paralelo com a Argentina, onde se considera rural uma "localidad" ou "aglomeracion" com menos de dois mil habitantes.

6 Vale a pena notar que seria necessária a soma das populações dos doze municípios para superar o ponto de corte para a definição de um único município como não rural, ou seja, os vinte mil habitantes. precariedade (ou, visto de outra forma, implica na perda do argumento da precariedade para reivindicar maior atenção) e resulta em ampliar a ideia de significância e relevância das escolas do campo.

\section{ESCOLAS DO CAMPO: MAIS E MELHORES DO QUE SE DIZ}

Para se ter uma ideia do subdimensionamento do que pode ser considerado como escolas do campo, recorre-se a tabulações realizadas pelo Observatório de Educação do Campo da UFSC 5 . Elas mostram que, dos doze menores municípios catarinenses - todos com menos de dois mil habitantes ${ }^{6}$, sete não têm sequer uma escola que apareça como rural nos dados do INEP.

Quadro 1 - Doze menores municípios catarinenses em população, número de escolas e escolas declaradas como urbanas e como rurais

\begin{tabular}{|l|c|c|c|c|}
\hline \multicolumn{1}{|c|}{ Município } & $\begin{array}{c}\text { População } \\
\text { Total }\end{array}$ & $\begin{array}{c}\text { Número } \\
\text { de } \\
\text { Escolas }\end{array}$ & $\begin{array}{c}\text { Escolas } \\
\text { declaradas } \\
\text { como } \\
\text { Urbanas }\end{array}$ & $\begin{array}{c}\text { Escolas } \\
\text { declaradas } \\
\text { como } \\
\text { Rurais }\end{array}$ \\
\hline Santiago do Sul & 1.465 & 3 & 3 & o \\
\hline Lajeado Grande & 1.490 & 3 & 3 & o \\
\hline Flor do Sertão & 1.588 & 2 & 2 & o \\
\hline Pres. Castello Branco & 1.725 & 8 & 4 & 4 \\
\hline Tigrinhos & 1.757 & 3 & 3 & 0 \\
\hline Paial & 1.763 & 4 & 2 & 2 \\
\hline Jardinópolis & 1.766 & 3 & 3 & 0 \\
\hline Macieira & 1.826 & 3 & 2 & 1 \\
\hline Barra Bonita & 1.878 & 4 & 1 & 3 \\
\hline Cunhataí & 1.882 & 6 & 3 & 3 \\
\hline S. Miguel da Boa Vista & 1.904 & 4 & 4 & 0 \\
\hline Ibiam & 1.945 & 2 & 2 & 0 \\
\hline \multicolumn{1}{|c|}{ Total } & 20.989 & 45 & 32 & 13 \\
\hline
\end{tabular}

Fonte: População - Censo Demográfico 2010 (IBGE); Escolas - Dados preliminares do Censo Escolar 2011, publicados no Diário Oficial da União, 22 de setembro de 2011 (INEP). Disponível em: <http://www. dataescolabrasil.inep.gov.br/dataEscolaBrasil/home.seam>.

Percebe-se que, das quarenta e cinco escolas existentes nesses doze pequenos municípios rurais, apenas treze são declaradas como rurais, e, em sete dos doze municípios, nenhuma escola é declarada como rural. Trata-se de mais um indicador de que para pensar Educação do Campo é necessário outro tipo de visão e, por consequência, de agregação e de análise de dados. É sabido que esses dados refletem a localização das escolas no perímetro urbano e que ela é o resultado de uma política pública verticalizada que fomenta a nucleação das escolas e o transporte das crianças e adolescentes. Como será exposto adiante, essa diretriz foi muito forte nos anos 1990 e tem, neste momento, um novo pico. Cabe, todavia, entender todas essas escolas como situadas "no campo". Somente assim será possível trabalhar na perspectiva de transformá-las em escolas "do campo". 
Para fortalecer esse posicionamento, foram elaborados o Quadro 2 e a Figura 1, identificando as escolas como rurais ou urbanas (e ambivalentes), seguindo os critérios apresentados anteriormente para classificar os municípios.

Quadro 2 - Localização das escolas em Santa Catarina, segundo classificação rural, urbana e ambivalente, de acordo com critérios INEP, Abramovay (2000) e Veiga (2002)
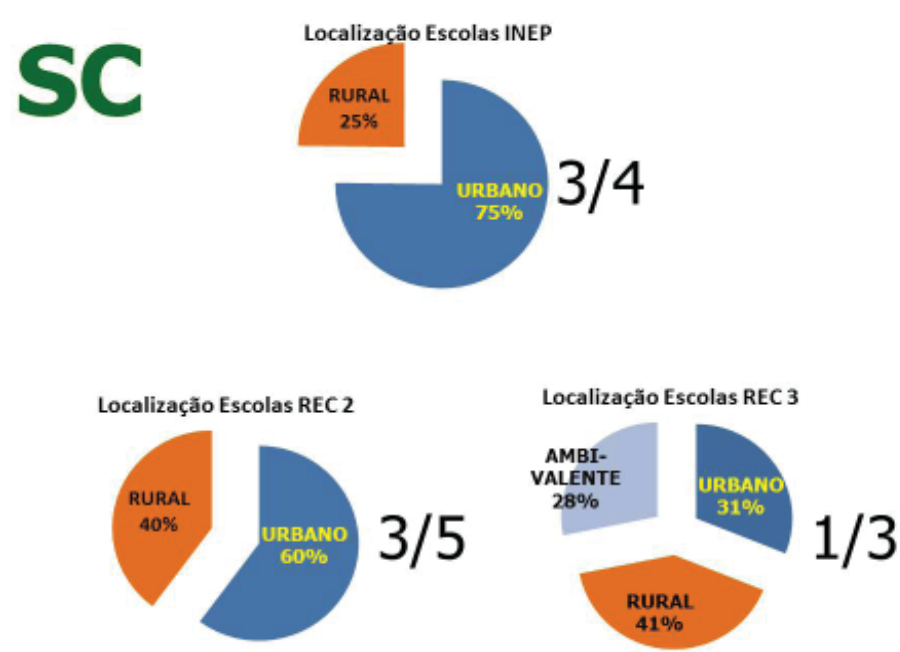

As escolas do campo têm mais significância do que se pensa. Parafraseando Veiga (2002), poder-se-ia dizer que as escolas catarinenses são menos urbanas do que normalmente se calcula, ou melhor, do que se anuncia. As escolas urbanas representam três em cada quatro escolas, se considerarmos a perspectiva INEP/IBGE; três em cinco, se consideramos o patamar de vinte mil habitantes; e uma a cada três, de acordo como recorte proposto por Veiga (2002).

É importante, contudo, assumir uma perspectiva histórica, mesmo que, nesse caso, se leve em conta, pelo menos por enquanto, apenas o "recorte" praticado pelo INEP com base no IBGE. Em uma série entre 1995 e 2011, com base no Censo Escolar, percebe-se nitidamente uma forte tendência à redução do número de escolas em atividade em Santa Catarina.

Gráfico1 - Localização das Escolas "em atividade" em Santa Catarina, período 1995-2011

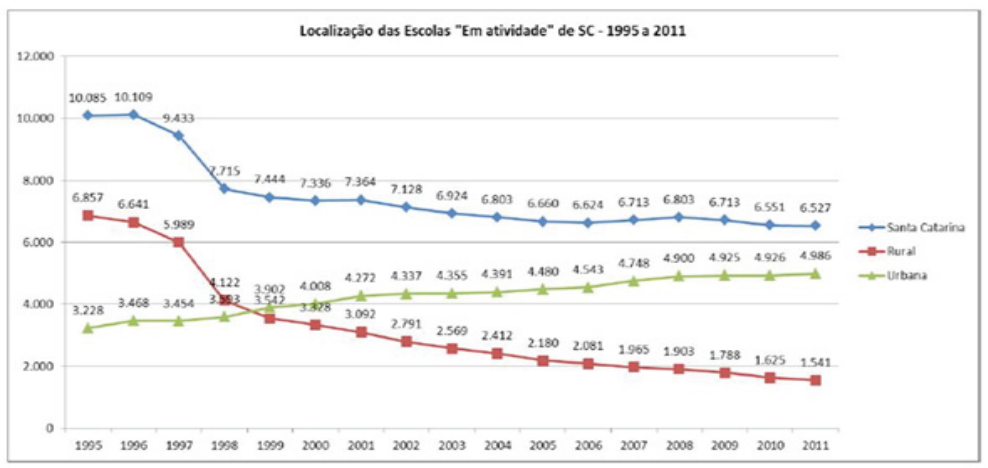

Fonte: Censo Escolar MEC, 1995-2011. 
Eram 10.085 escolas, em 1995, e são 6.527, em 2011. Tal redução é explicada pela paralisação ou extinção de escolas rurais. Elas eram 6.857, em 1995, e somavam, em 2011, menos de um quarto disso (1.541). Enquanto isso, o número de escolas urbanas cresceu, no mesmo período, de 3.228 para 4.896. Esse fenômeno reflete diretamente o processo que combinou nucleação ou agrupamento de escolas dentro dos perímetros urbanos dos municípios, combinado com o transporte escolar. Ao mesmo tempo, como indica o Gráfico 2, eram "fechadas" as escolas rurais, as quais podemos associar as pejorativamente chamadas de "escolinhas" ou formalmente designadas como "isoladas", situadas nas localidades do "interior" dos mesmos municípios que, em geral, têm no seu conjunto características socioeconômicas, culturais e políticas de rural.

Gráfico 2 - Localização das Escolas "paralisadas e extintas" em Santa Catarina, período 1995-2011

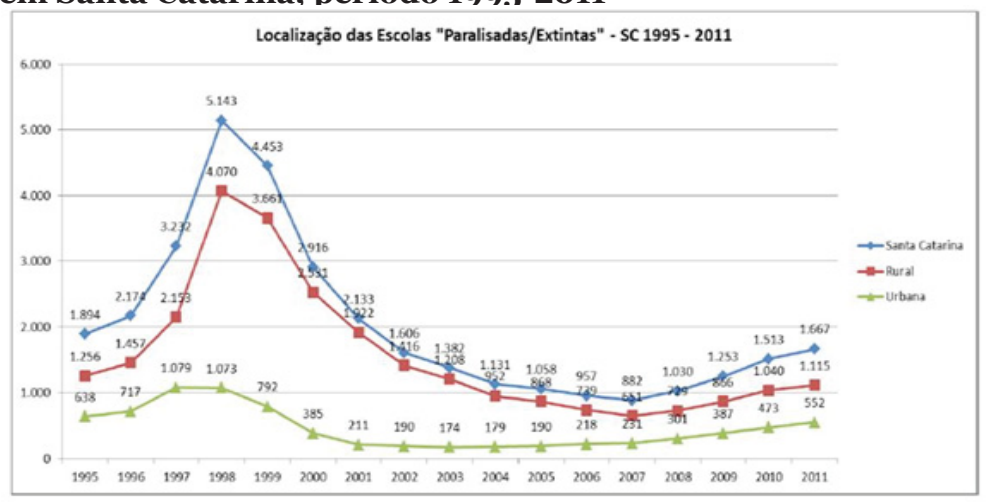

Fonte: Censo Escolar MEC, 1995-2011.

Embora não seja diretamente o foco deste estudo, é indispensável notar uma concentração do processo de nucleação de escolas e transporte de estudantes no período de 1995 a 2000, assim como um retorno da inflexão positiva da curva de paralização-extinção de escolas rurais a partir de 2007 e que se mantém até 2011. Esse fenômeno fica ainda mais evidente no Gráfico 3.

Gráfico 3 - Escolas rurais segundo critérios do INEP e situação de funcionamento em Santa Catarina, período 1995-2011.

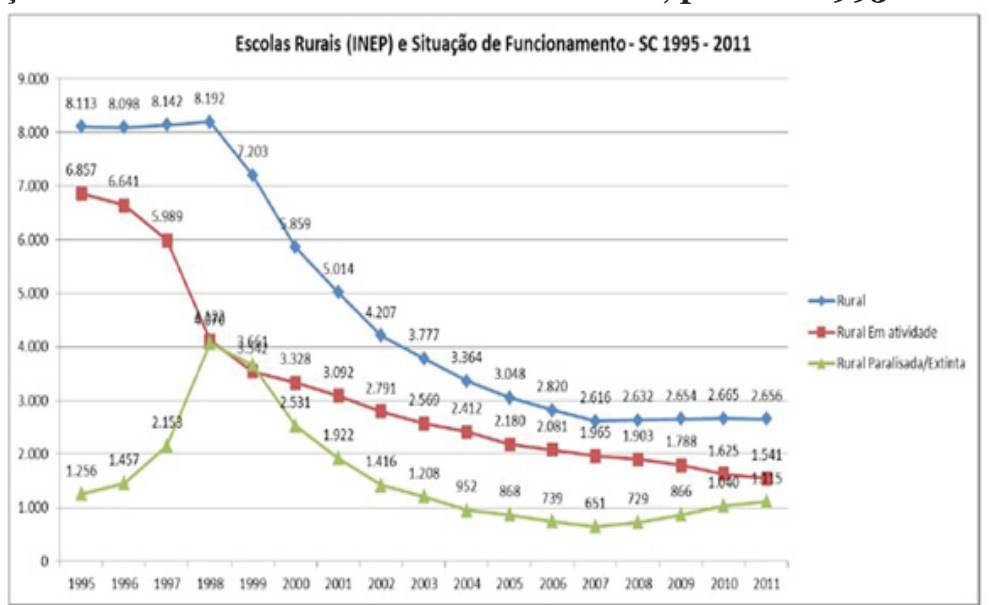

Fonte: Censo Escolar MEC, 1995-2011. 
Sinaliza-se para a existência de determinantes políticos e condicionantes estratégicos e econômicos em escala "macro", que não podem, portanto, ser explicados pelas dinâmicas dos municípios ou por opções localizadas das administrações municipais. Entre 1995 e 1999, o número de escolas rurais em atividade caiu em Santa Catarina, de 6.857 para 3.342, ou seja, em quatro anos o número de escolas rurais caiu mais do que pela metade. Não há mudanças demográficas, econômicas ou socioculturais nos municípios que possam explicar esse movimento combinado e articulado.

Voltando ao Censo Escolar de 2010 e ao entendimento de escola rural, é fundamental considerar também o número de matrículas. Pelos critérios do INEP, em 2010, 124.338 estudantes estavam matriculados em escolas rurais, o que corresponderia a apenas $7,4 \%$ das matrículas totais. Se seguirmos a aproximação apresentada anteriormente, que considera municípios rurais aqueles com até vinte mil habitantes, o número de estudantes matriculados mais do que triplicaria e o percentual subiria para $25,4 \%$. Com a aproximação, a partir dos critérios de José Eli da Veiga (2004), que têm os patamares populacionais em 50 e 100 mil e incluem a densidade demográfica, esse número ganha praticamente mais quarenta mil estudantes e a participação percentual eleva-se a 27,8\%. Olhando pelo prisma das escolas consideradas urbanas, a diferença no peso que têm as matrículas é ainda mais significativa.

Quadro 3 - Número de matrículas e localização das escolas em Santa Catarina, segundo classificação rural, urbana e ambivalente, de acordo com critérios INEP, Abramovay (2000) e Veiga (2002)

\begin{tabular}{|c|r|c|r|r|r|r|}
\hline \multirow{2}{*}{$\begin{array}{l}\text { Local. da } \\
\text { escola }\end{array}$} & \multicolumn{2}{|c|}{ INEP } & \multicolumn{2}{c|}{ REC2 } & \multicolumn{2}{c|}{ REC 3 } \\
\cline { 2 - 7 } & Matrículas & $\%$ & Matrículas & $\%$ & Matrículas & $\%$ \\
\hline Rural & 124338 & 7,4 & 429551 & 25,4 & 469235 & 27,8 \\
\hline Ambivalente & & & & & 511313 & 30,3 \\
\hline Urbano & 1564343 & 92,6 & 1259130 & 74,6 & 708133 & 41,9 \\
\hline Total & 1688681 & 100 & 1688681 & 100 & 1688681 & 100 \\
\hline
\end{tabular}

Se nos critérios utilizados pelo INEP as matrículas nas escolas urbanas representam 92,6\%, no recorte que considera como urbanas aquelas escolas situadas em municípios com mais de vinte mil habitantes esse percentual cai para $74,6 \%$. Se concebermos como urbanas apenas as escolas situadas em municípios urbanos nos critérios propostos por Veiga (2002), tal participação cai para 41,9\%. Uma visualização mais clara é possível na Figura 2 a seguir. 
Figura 2 - Número e percentual de matrículas em Santa Catarina, considerando localização das escolas, segundo classificação rural, urbana e ambivalente, de acordo com critérios INEP, Abramovay (2000), REC2; e Veiga (2002), REC 3

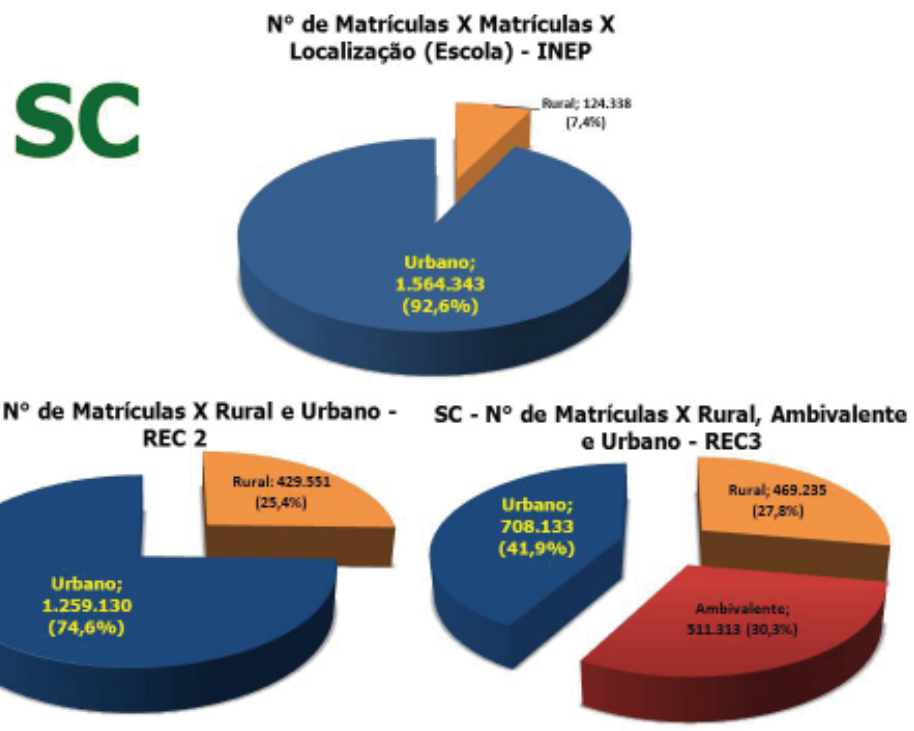

Resta, ainda, discutir uma questão relevante quando se trabalha com educação em contextos rurais, independentemente da perspectiva de ruralidade a orientar tal discussão. Trata-se do transporte escolar público, seja aquele considerado "intracampo" (de localidades fora da sede dos municípios ou de distritos para escolas também situadas fora do que é considerado urbano), seja aquele considerado rural-urbano. Sabe-se que, em geral, quem assegura esse serviço são as administrações municipais. O governo de Santa Catarina busca convênios com as prefeituras, para assegurar que os estudantes do ensino médio matriculados na rede estadual e que moram nas comunidades que recebem esse serviço sejam transportados com a mesma estrutura e logística. Pode-se afirmar, grosso modo, que o transporte só existe para os habitantes do que seja julgado meio rural.

Quadro 4 - Matrículas e transporte escolar público nas escolas em Santa Catarina, considerando localização das escolas, segundo classificação rural, urbana e ambivalente, de acordo com critérios INEP, Abramovay (200o), REC2, e Veiga (2002), REC 3.

\begin{tabular}{|c|c|c|c|c|c|c|c|c|c|}
\hline \multirow{2}{*}{$\begin{array}{c}\text { Matrículas/ } \\
\text { Localização } \\
\text { da Escola/ } \\
\text { Transporte } \\
\text { escolar }\end{array}$} & \multicolumn{3}{|c|}{ INEP } & \multicolumn{3}{|c|}{ REC 2} & \multicolumn{3}{|c|}{ REC 3} \\
\hline & $\begin{array}{c}\text { Não } \\
\text { Utiliza }\end{array}$ & Utiliza & Total & $\begin{array}{l}\text { Não } \\
\text { Utiliza }\end{array}$ & Utiliza & Total & $\begin{array}{c}\text { Não } \\
\text { Utiliza }\end{array}$ & Utiliza & Total \\
\hline Rural & $\begin{array}{c}41368 \\
(33,3 \%)\end{array}$ & $\begin{array}{c}82970 \\
(66,7 \%)\end{array}$ & $\begin{array}{l}124338 \\
(100 \%)\end{array}$ & $\begin{array}{l}218225 \\
(50,8 \%)\end{array}$ & $\begin{array}{l}211326 \\
(49,2 \%)\end{array}$ & $\begin{array}{l}429551 \\
(100 \%)\end{array}$ & $\begin{array}{l}256581 \\
(54,7 \%)\end{array}$ & $\begin{array}{l}212654 \\
(45,3 \%)\end{array}$ & $\begin{array}{l}469235 \\
(100 \%)\end{array}$ \\
\hline Ambivalente & & & & & & & \begin{tabular}{|l|}
409991 \\
$(80,2 \%)$ \\
\end{tabular} & $\begin{array}{l}101322 \\
(19,8 \%) \\
\end{array}$ & \begin{tabular}{|l}
511313 \\
$(100 \%)$ \\
\end{tabular} \\
\hline Urbano & $\begin{array}{c}1283054 \\
(82 \%)\end{array}$ & \begin{tabular}{|c|}
281289 \\
$(18 \%)$
\end{tabular} & $\begin{array}{c}1564343 \\
(100 \%)\end{array}$ & $\begin{array}{l}1106197 \\
(87,9 \%)\end{array}$ & $\begin{array}{l}152933 \\
(12,1 \%)\end{array}$ & $\begin{array}{c}1259130 \\
(100 \%)\end{array}$ & $\begin{array}{l}657850 \\
(92,9 \%)\end{array}$ & $\begin{array}{c}50283 \\
(7,1)\end{array}$ & \begin{tabular}{|l}
708133 \\
$(100 \%)$
\end{tabular} \\
\hline Total & $\begin{array}{l}1324422 \\
(78,4 \%)\end{array}$ & $\begin{array}{l}364259 \\
(21,6 \%)\end{array}$ & $\begin{array}{c}1688681 \\
(100 \%)\end{array}$ & $\begin{array}{l}1324422 \\
(78,4 \%)\end{array}$ & $\begin{array}{l}364259 \\
(21,6 \%)\end{array}$ & $\begin{array}{l}1688681 \\
(100 \%)\end{array}$ & $\begin{array}{l}1324422 \\
(78,4 \%)\end{array}$ & $\begin{array}{l}364259 \\
(21,6 \%)\end{array}$ & $\begin{array}{l}1688681 \\
(100 \%)\end{array}$ \\
\hline
\end{tabular}


Seguindo o critério do INEP, verifica-se que 82.970 estudantes de escolas situadas no meio rural utilizam transporte escolar público $(66,7 \%)$. Nota-se que nas escolas situadas no meio urbano apenas $18 \%$ dos estudantes utilizam o mesmo serviço. É preciso, todavia, considerar os números absolutos: 281.289 estudantes de escolas consideradas urbanas pelo INEP utilizam transporte público. Isso corresponde a 77\% dos 364.259 estudantes que fazem uso desse serviço em Santa Catarina. Esses números serão melhor elucidados se forem considerados os "recortes" 2 e 3. Nos municípios com menos de vinte mil habitantes (REC 2), são transportados 211.326 estudantes (49,2\%), enquanto 218.225 (50,8\%) não utilizam transporte. Pode-se inferir, assim, que esse acréscimo de quase $130 \mathrm{mil}$ estudantes que utilizam o transporte signifique crianças e adolescentes que moram em localidades fora da sede do município e de distritos e são transportados para escolas nela situadas (e por isso, consideradas urbanas pelo IBGE e INEP). Esse fenômeno tem clara relação com o processo de nucleação de escolas combinada com transporte de estudantes, isto é, há claros indicativos de que temos escolas situadas em área considerada urbana e que atendem predominantemente a populações do campo. Exatamente a novidade na definição de "escola do campo" trazida pelo Decreto ${ }^{0} 7.352$ (Brasil, 2010).

Esses mesmos indícios surgem no "recorte 3". Nota-se que os estudantes que utilizam o transporte público em municípios urbanos (neste REC 3, com mais de cem mil habitantes) são pouco mais de cinquenta mil e representam apenas 7,1\% do total (708.1133). Nos municípios essencialmente rurais (menos de cinquenta mil habitantes e densidade demográfica inferior a 80 habitantes por quilometro quadrado), 212.654 estudantes utilizam o transporte público, o que reforça a perspectiva já colocada acima para o "recorte 2". As escolas do campo são, portanto, mais importantes do que se avalia.

O interessante é que refazer esses cálculos implica, também, em uma nova visão sobre as infraestruturas disponíveis para o trabalho pedagógico nas escolas do campo. Com objetivo de ilustrar e fazer pensar, escolheram-se os itens ligados à informática: se há um laboratório de informática (Quadro 5) e acesso à internet (Quadro 6). Procurou-se agregar os dados, pois a simples existência de computadores na escola não é, por si, revelador de qualquer melhoria para os estudantes. O laboratório de informática dá uma ideia melhor, mas essa informação precisa ser complementada com a possibilidade de acesso à internet para possíveis pesquisas e ferramentas de comunicação. 
Quadro 5 - Infraestruturas existentes nas escolas em Santa Catarina: laboratório de informática, considerando localização das escolas, segundo classificação rural, urbana e ambivalente, de acordo com critérios INEP, Abramovay (2000), REC2; e Veiga (2002), REC 3

\begin{tabular}{|c|c|c|c|c|c|c|c|c|c|}
\hline \multirow{2}{*}{$\begin{array}{l}\text { Local da } \\
\text { Escola/ } \\
\text { Lab. } \\
\text { de Infor- } \\
\text { mática }\end{array}$} & \multicolumn{3}{|c|}{ INEP } & \multicolumn{3}{|c|}{ REC 2} & \multicolumn{3}{|c|}{ REC $3_{3}$} \\
\hline & Não & Sim & al & Não & Sim & Total & Não & Sim & Total \\
\hline Rural & $\begin{array}{c}1064 \\
(65,5 \%)\end{array}$ & $\begin{array}{c}561 \\
(34,5 \%)\end{array}$ & $\begin{array}{c}1625 \\
(100 \%)\end{array}$ & $\mid \begin{array}{c}1531 \\
(58,7 \%)\end{array}$ & $\begin{array}{c}1079 \\
(41,3 \%)\end{array}$ & $\begin{array}{c}2610 \\
(100 \%)\end{array}$ & $\begin{array}{c}1544 \\
(57,8 \%)\end{array}$ & $\begin{array}{c}1126 \\
(42,2 \%)\end{array}$ & $\begin{array}{c}2670 \\
(100 \%)\end{array}$ \\
\hline $\begin{array}{c}\text { Ambiva- } \\
\text { lente }\end{array}$ & & & & & & & $\begin{array}{c}944 \\
(51,1 \%)\end{array}$ & $\begin{array}{c}902 \\
(48,9 \%)\end{array}$ & $\begin{array}{c}1846 \\
(100 \%)\end{array}$ \\
\hline Urbano & $\begin{array}{c}2406 \\
(48,8 \%)\end{array}$ & $\begin{array}{c}2520 \\
(51,2 \%)\end{array}$ & $\begin{array}{c}4926 \\
(100 \%)\end{array}$ & $\begin{array}{c}1939 \\
(49,2 \%)\end{array}$ & $\begin{array}{c}2002 \\
(50,8 \%)\end{array}$ & $\begin{array}{c}3941 \\
(100 \%)\end{array}$ & $\begin{array}{c}982 \\
(48,3 \%)\end{array}$ & $\begin{array}{c}1053 \\
(51,7 \%)\end{array}$ & $\begin{array}{c}2035 \\
(100 \%)\end{array}$ \\
\hline Total & $\begin{array}{c}3470 \\
(53,0 \%)\end{array}$ & $\begin{array}{c}3081 \\
(47,0 \%)\end{array}$ & $\begin{array}{c}6551 \\
(100 \%)\end{array}$ & $\begin{array}{c}3470 \\
(53,0 \%)\end{array}$ & $\begin{array}{c}3081 \\
(47,0 \%)\end{array}$ & $\begin{array}{c}6551 \\
(100 \%)\end{array}$ & $\begin{array}{c}3470 \\
(53,0 \%)\end{array}$ & $\begin{array}{c}3081 \\
(47,0 \%) \\
\end{array}$ & $\begin{array}{c}6551 \\
(100 \%) \\
\end{array}$ \\
\hline
\end{tabular}

Nota-se que, seguindo os critérios do INEP, apenas 561 escolas rurais dispõem de um laboratório de informática, o que representaria $34,5 \%$ do total de 1.625 escolas situadas fora das sedes de municípios ou distritos. Usando o "recorte 2" para a aproximação da escola rural, o número das que dispõem de laboratório de informática cresce para 1.079, aumentando o percentual para 41,3\%. No "recorte 3", são 1126 escolas com esse tipo de laboratório, e o percentual alcança $42,2 \%$. Certamente, esses números são baixos. Eles precisam ser, todavia, cotejados com aqueles relativos à escola considerada urbana. Qualquer que seja o critério de delimitação (INEP, recorte 1 ou 2), praticamente metade das "escolas urbanas" não dispõe de um laboratório de informática.

No que se refere à internet, apenas 499 escolas rurais $(30,7 \%)$ têm acesso a essa ferramenta cada vez mais indispensável. Com o "recorte 2", esse número praticamente triplica, passando para 1.476 (56,6\%). Para o "recorte 3", os números são muito parecidos: 1.505 e percentual de 56,4\%. Esse quantitativo é explicado pela própria distribuição desse tipo de infraestrutura e serviços, normalmente restritos a aglomerações populacionais mais importantes ou, no caso de municípios com baixa população e densidade demográfica, aos perímetros urbanos. Ou seja, não são apenas as escolas "do interior" dos municípios que não dispõem de internet. Observa-se que há uma diferença frente à situação dos laboratórios de informática. Aproximadamente 80\% das escolas consideradas urbanas dispõem de acesso à internet. Isso indica, entretanto, que em boa parte dessas escolas a internet não serve para pesquisas e outras atividades de ensino que envolvam diretamente os estudantes.

Quadro 6 - Infraestruturas existentes nas escolas em Santa Catarina: acesso à internet, considerando localização das escolas, segundo classificação rural, urbana e ambivalente, de acordo com critérios INEP, Abramovay (2000), REC2; e Veiga (2002), REC 3

\begin{tabular}{|c|c|c|c|c|c|c|c|c|c|}
\hline $\begin{array}{c}\text { Local da } \\
\text { Escola } \\
\begin{array}{c}\text { Acesso à } \\
\text { internet }\end{array}\end{array}$ & \multicolumn{3}{|c|}{ INEP } & \multicolumn{3}{c|}{ REC 2 } & \multicolumn{3}{c|}{ REC 3 } \\
\hline Rural & $\begin{array}{c}1126 \\
(69,3 \%)\end{array}$ & $\begin{array}{c}499 \\
30,7 \%)\end{array}$ & $\begin{array}{c}1625 \\
(100 \%)\end{array}$ & $\begin{array}{c}1134 \\
(43,4 \%)\end{array}$ & $\begin{array}{c}1476 \\
(56,6 \%)\end{array}$ & $\begin{array}{c}2610 \\
(100 \%)\end{array}$ & $\begin{array}{c}1165 \\
(43,6 \%)\end{array}$ & $\begin{array}{c}1505 \\
(56,4 \%)\end{array}$ & $\begin{array}{c}2670 \\
(100 \%)\end{array}$ \\
\hline $\begin{array}{c}\text { Ambiva- } \\
\text { lente }\end{array}$ & & & & & & $\begin{array}{c}595 \\
(32,2 \%)\end{array}$ & $\begin{array}{c}1251 \\
(67,8 \%)\end{array}$ & $\begin{array}{c}1846 \\
(100 \%)\end{array}$ \\
\hline Urbano & $\begin{array}{c}1055 \\
(21,4 \%)\end{array}$ & $\begin{array}{c}3871 \\
(78,8 \%)\end{array}$ & $\begin{array}{c}4926 \\
(100 \%)\end{array}$ & $\begin{array}{c}1047 \\
(26,6 \%)\end{array}$ & $\begin{array}{c}2894 \\
(73,4 \%)\end{array}$ & $\begin{array}{c}3941 \\
(100 \%)\end{array}$ & $\begin{array}{c}421 \\
(20,7 \%)\end{array}$ & $\begin{array}{c}1614 \\
(79,3 \%)\end{array}$ & $\begin{array}{c}2035 \\
(100 \%)\end{array}$ \\
\hline Total & $\begin{array}{c}2181 \\
(33,3 \%)\end{array}$ & $\begin{array}{c}4370 \\
(66,7 \%)\end{array}$ & $\begin{array}{c}6551 \\
(100 \%)\end{array}$ & $\begin{array}{c}2181 \\
(33,3 \%)\end{array}$ & $\begin{array}{c}4370 \\
(66,7 \%)\end{array}$ & $\begin{array}{c}6551 \\
(100 \%)\end{array}$ & $\begin{array}{c}2181 \\
(33,3 \%)\end{array}$ & $\begin{array}{c}4370 \\
(66,7 \%)\end{array}$ & $\begin{array}{c}6551 \\
(100 \%)\end{array}$ \\
\hline
\end{tabular}


Em relação a outros indicadores significativos, os dados sobre professores não estavam disponíveis e informações sobre biblioteca e laboratório de ciências refletem uma insuficiência mais geral.

Quadro 7 - Infraestruturas existentes nas escolas em Santa Catarina: biblioteca, considerando localização das escolas, segundo classificação rural, urbana e ambivalente, de acordo com critérios INEP, Abramovay (2000), REC2; e Veiga (2002), REC 3

\begin{tabular}{|c|c|c|c|c|c|c|c|c|c|}
\hline \multirow{2}{*}{$\begin{array}{c}\text { Local da } \\
\text { Escola/ } \\
\text { Biblioteca }\end{array}$} & \multicolumn{3}{|c|}{ INEP } & \multicolumn{3}{|c|}{ REC 2} & \multicolumn{3}{|c|}{$\mathrm{REC}_{3}$} \\
\hline & Não & Sim & Total & Não & Sim & Total & Não & Sim & Total \\
\hline Rural & $\begin{array}{c}1154 \\
(71,0 \%)\end{array}$ & $\begin{array}{c}471 \\
(29,0 \%)\end{array}$ & $\begin{array}{c}1625 \\
(100 \%)\end{array}$ & $\begin{array}{c}1577 \\
(60,4 \%)\end{array}$ & $\begin{array}{c}1033 \\
(39,6 \%)\end{array}$ & $\begin{array}{c}2610 \\
(100 \%)\end{array}$ & $\begin{array}{c}1609 \\
(60,3 \%)\end{array}$ & $\begin{array}{c}1061 \\
(39,7 \%)\end{array}$ & $\begin{array}{c}2670 \\
(100 \%)\end{array}$ \\
\hline $\begin{array}{c}\text { Ambiva- } \\
\text { lente }\end{array}$ & & & & & & & \begin{tabular}{|c|}
875 \\
$(47,4 \%)$ \\
\end{tabular} & $\begin{array}{c}971 \\
(52,6 \%) \\
\end{array}$ & $\begin{array}{c}1846 \\
(100 \%) \\
\end{array}$ \\
\hline Urbano & $\begin{array}{c}2195 \\
(44,6 \%) \\
\end{array}$ & $\begin{array}{c}2731 \\
(55,4 \%) \\
\end{array}$ & $\begin{array}{c}4926 \\
(100 \%) \\
\end{array}$ & $\begin{array}{c}1772 \\
(45,0 \%) \\
\end{array}$ & $\begin{array}{c}2169 \\
(55,0 \%) \\
\end{array}$ & $\begin{array}{c}3941 \\
(100 \%) \\
\end{array}$ & $\begin{array}{c}865 \\
(42,5 \%) \\
\end{array}$ & $\begin{array}{c}1170 \\
(57,5 \%) \\
\end{array}$ & $\begin{array}{r}2035 \\
(100 \%) \\
\end{array}$ \\
\hline Total & $\begin{array}{c}3349 \\
(51,1 \%)\end{array}$ & $\begin{array}{c}3202 \\
(48,9 \%)\end{array}$ & $\begin{array}{c}6551 \\
(100 \%)\end{array}$ & $\begin{array}{c}3349 \\
(51,1 \%)\end{array}$ & $\begin{array}{c}3202 \\
(48,9 \%)\end{array}$ & $\mid \begin{array}{c}6551 \\
(100 \%)\end{array}$ & $\begin{array}{c}3349 \\
(51,1 \%)\end{array}$ & $\begin{array}{c}3202 \\
(48,9 \%)\end{array}$ & $\begin{array}{c}6551 \\
(100 \%)\end{array}$ \\
\hline
\end{tabular}

Constata-se que apenas $48,9 \%$ das escolas catarinenses dispõem de uma biblioteca e, qualquer que seja o "recorte", apenas pouco mais da metade das escolas urbanas tem esse recurso indispensável. Os dados do INEP indicam uma grande precariedade das escolas rurais nesse item (29\% delas possuiria bibliotecas), proporção que melhora com os dois outros "recortes", subindo para em torno de $40 \%$.

Com relação a laboratório de ciências (Quadro 8), apenas próximo de um décimo das escolas catarinenses tem esse recurso e, quaisquer que sejam os critérios, apenas 16\% das escolas urbanas dispõem dele. Nas escolas rurais, tal recurso é raro, qualquer que seja a classificação, passando do grotesco 1,6\%, no critério INEP, para irrisórios oito e meio a nove por cento nos outros dois recortes.

Quadro 8 - Infraestruturas existentes nas escolas em Santa Catarina: laboratório de ciências, considerando localização das escolas, segundo classificação rural, urbana e ambivalente, de acordo com critérios INEP, Abramovay (2000), REC2; e Veiga (2002), REC 3

\begin{tabular}{|c|c|c|c|c|c|c|c|c|c|}
\hline $\begin{array}{c}\text { Local da } \\
\text { Escola/ } \\
\text { Laboratório } \\
\text { de ciências }\end{array}$ & \multicolumn{3}{|c|}{ INEP } & \multicolumn{3}{c|}{ REC 2 } & \multicolumn{3}{c|}{ REC 3 } \\
\hline Rural & $\begin{array}{c}1599 \\
(98,4 \%)\end{array}$ & $\begin{array}{c}26 \\
(1,6 \%)\end{array}$ & $\begin{array}{c}1625 \\
(100 \%)\end{array}$ & $\begin{array}{c}2389 \\
(91,5 \%)\end{array}$ & $\begin{array}{c}221 \\
(8,5 \%)\end{array}$ & $\begin{array}{c}2610 \\
(100 \%)\end{array}$ & $\begin{array}{c}2432 \\
(91,1 \%)\end{array}$ & $\begin{array}{c}238 \\
(8,9 \%)\end{array}$ & $\begin{array}{c}2670 \\
(100 \%)\end{array}$ \\
\hline $\begin{array}{c}\text { Ambiva- } \\
\text { lente }\end{array}$ & & & & & & & $\begin{array}{c}1570 \\
(85,0 \%)\end{array}$ & $\begin{array}{c}276 \\
(15,0 \%)\end{array}$ & $\begin{array}{c}1846 \\
(100 \%)\end{array}$ \\
\hline Urbano & $\begin{array}{c}4113 \\
(83,5 \%)\end{array}$ & $\begin{array}{c}813 \\
(16,5 \%)\end{array}$ & $\begin{array}{c}4926 \\
(100 \%)\end{array}$ & $\begin{array}{c}3333 \\
(84,3 \%)\end{array}$ & $\begin{array}{c}618 \\
(15,7 \%)\end{array}$ & $\begin{array}{c}3941 \\
(100 \%)\end{array}$ & $\begin{array}{c}1710 \\
(84,0 \%)\end{array}$ & $\begin{array}{c}325 \\
(16,0 \%)\end{array}$ & $\begin{array}{c}2035 \\
(100 \%)\end{array}$ \\
\hline Total & $\begin{array}{c}5712 \\
(87,2 \%)\end{array}$ & $\begin{array}{c}839 \\
(12,8 \%)\end{array}$ & $\begin{array}{c}6551 \\
(100 \%)\end{array}$ & $\begin{array}{c}5712 \\
87,2\end{array}$ & $\begin{array}{c}839 \\
(12,8 \%)\end{array}$ & $\begin{array}{c}6551 \\
(100 \%)\end{array}$ & $\begin{array}{c}5712 \\
87,2\end{array}$ & $\begin{array}{c}839 \\
(12,8 \%)\end{array}$ & $\begin{array}{c}6551 \\
(100 \%)\end{array}$ \\
\hline
\end{tabular}

Tais dados contribuem para evitar associar, como é frequente na literatura sobre educação do campo, a escola situada no campo com a carência de tudo. Esse olhar enviesado é resultado, como procuramos indicar, de uma delimitação arbitrária de rural que, como o próprio Movimento de Educação do Campo já apontou, em 2004, oferece "uma falsa visão" da população - e, por consequência, da escola do campo. Com o amplo e rápido processo de nucleação 
das escolas, associado ao transporte escolar, "sobraram" fora dos perímetros urbanos de municípios rurais inseridos em territórios rurais apenas pequenas escolas situadas em localidades isoladas, onde seria mais caro, e até ilegal e ilegítimo (para não dizer, desumano), "puxar" (transportar) as crianças.

Dada a baixa densidade demográfica dessas localidades e a miopia das administrações municipais, restaram, no "interior" (ou no "rural", como é considerado pelo IBGE), quase que tão somente escolas de séries iniciais do ensino fundamental, com uma só sala de aula e, em geral, unidocente e multisseriada. Apenas para tais escolas, o dirigente assinala com um " $x$ " a opção rural para a localização no formulário do INEP (ou, mais propriamente, já se depara com este item bloqueado nos sistema online). Assim, para os dados oficiais, esta é a escola situada no meio rural. Embora ela faça parte do campo, não é, contudo a escola "no" e "do" campo proposta pelo Movimento de Educação do Campo, assim como não é a escola do campo do Decreto 7.352, de 2010 (Brasil, 2010).

\section{OUTRAS FORMAS DE DELIMITAÇÃO: O QUE A VIZINHA ARGENTINA NOS FAZ PENSAR}

Dirigir nosso foco para outras experiências nacionais de classificação de escolas rurais pode nos ajudar a melhor compreender a experiência brasileira. Consideramos, obviamente, a possibilidade de se instalar no Brasil uma intenção e uma prática tendente à hegemonia de construção social, que permita que as escolas situadas "no campo" levem efetivamente em conta as necessidades, particularidades e potencialidades das populações que tornam vivos os seus territórios rurais. Nesse caso, importa evidenciar um exemplo que pode ser útil tanto à prática de gestão dos sistemas educacionais oficiais quanto ao contra-hegemônico Movimento de Educação do Campo. Ainda que brevemente, e somente a título de exemplo, vejamos o caso da República Argentina.

Para tratar da Educação Rural no sistema educativo nacional da Argentina, é preciso partir de algumas perguntas: o que é considerado espaço rural no país vizinho? Quais são as condições para se declarar uma escola como "escola rural" naquele país? Qual é o significado atribuído à educação rural como modalidade, tanto do ponto de vista das políticas públicas, como do ponto de vista das práticas pedagógicas? Essas definições conceituais de caráter operacional para a educação em contextos rurais fazem parte explicitamente da "Resolução do Conselho Federal de Educação n 109/10", da República Argentina, que disciplina a "Educación Rural enel Sistema Educativo Nacional", conforme determina a "Lei de Educação Nacional" (LEN), de 2006, sob o n ${ }^{0} 26.206$.

Uma primeira observação, sobre a qual chamamos atenção, é a de que a educação rural no sistema argentino considera um "anacronismo tentar definir o espaço rural 
como uno e homogêneo em oposição ao espaço urbano" (Argentina, 2010, tradução nossa). Para o sistema educativo argentino,

Os destinatários das políticas educativas para a ruralidade habitam regiões muito diversas que incluem grandes espaços de produções extensivas destinadas aos agronegócios em grande escala, assim como um amplo espectro no que é necessário considerar médios e pequenos produtores, agricultores familiares que produzem quase exclusivamente para a subsistência, famílias migrantes, famílias de desocupados que vivem em zonas isoladas e muito dispersas. Hoje, a pluriatividade (multiactividad - que inclui a diversificação do trabalho em indústrias e serviços) e a pluralidade de atores que trabalham e habitam nos ambientes rurais vão caracterizando espaços muito diferentes. (Argentina, 2010, tradução nossa).

Diante do reconhecimento de tal diversidade do rural, o Governo da República Argentina toma uma decisão, que entendemos como eminentemente política, de identificar a "Agricultura Familiar" (AF) como uma categoria de análise e, por conseguinte, os agricultores familiares como os principais destinatários das políticas e programas de educação rural.

A AF é definida como uma forma de vida, uma questão cultural. Ela tem como objetivo, para além da atividade agrícola que se realize, a reprodução social das famílias em condições dignas. Partindo dessas perspectivas e considerando as transformações no campo, atualmente a escola rural, em qualquer dos níveis, atende fundamentalmente os filhos dos "agricultores familiares", no amplo espectro mencionado (Argentina, 2010, tradução nossa).

Parece evidente que a educação rural, considerada como um conjunto de políticas, normas e procedimentos pedagógicos, que se constitui, enfim, em modalidade específica, é tomada como instrumento a serviço de um determinado modelo de desenvolvimento rural, no caso, definido como "agricultura familiar". Através do conceito de AF, politicamente mobilizado - que extrapola a atividade agrícola stricto sensu para fazer-se "forma de vida" e "questão cultural" -, é possível perceber, entre outros significados, que os sujeitos a quem se destina a educação rural (os filhos dos agricultores familiares) podem estar situados no mais recôndito isolamento, como também em pequenos aglomerados humanos. Aglomerados que, se vistos pelos critérios administrativos de delimitação rural-urbano adotados no Brasil (IBGE), seriam em boa parte classificados como urbanos, da mesma forma que as pessoas neles residem.

Outra observação importante a destacar é que os policymakers argentinos compreenderam que, na medida em que a modalidade de educação rural impõe ao Estado edu- 
cador maiores custos orçamentários relativos, pois suscita programas especiais caros, o texto da norma deveria ser seguido de critérios. Com isso, buscaram evitar distorções nos atos que decidem se determinada escola será ou não considerada rural. Observa-se que tais decisões sobre cada unidade escolar são compartilhadas entre a autoridade executiva federal e as autoridades executivas das respectivas províncias (não há informação sobre a participação popular ou de qualquer organização da sociedade civil nesse processo decisório).

Em resumo, no país vizinho não existe um critério geral e invariável, como é o caso no Brasil, onde a "situação por dependência administrativa" caracteriza uma escola como situada no "perímetro urbano" ou situada na "zona rural". Lá, o grau de "isolamento" e o grau de "dispersão" das famílias são tomados como variáveis que relativizam a classificação da escola rural, de acordo com seus respectivos contextos. Desse modo, e por consequência, aquelas mais isoladas e de reduzidas matrículas são tomadas como referência extrema para a maior atenção das autoridades institucionais pertinentes. Desde este "grau de ruralidade" da escola e, levando-se em conta o conceito básico de AF, seguem-se a criação e o fomento de programas e projetos governamentais próprios. Em outros termos, cada escola pode ser declarada como "mais rural" ou "menos rural", a depender do contexto em que se insere, e, pelo menos na projeção ideal, a atenção dos órgãos públicos se intensifica em sentido inversamente proporcional ao "grau de ruralidade". Enfim, conforme é possível observar, trata-se do enfrentamento da questão da escola rural rigorosamente a partir de uma ampla "Sociologia da Educação Rural”.

\section{PARA CONCLUIR (ESSE PASSO INICIAL)}

Como se buscou apontar ao longo desta reflexão, existem proposições diferenciadas para se enfrentar, teórica e politicamente, a questão da delimitação campo-cidade. E, dada a amplitude, a diversidade e a complexidade da realidade brasileira, nenhuma dessas demarcações pode ser tomada como regra geral e completa. Espera-se que, apontando experiências de governança de outros povos, como o caso Argentino, ocorra uma sensibilização para a elaboração de parâmetros de delimitação mais complexos e específicos às realidades dos territórios rurais para dar conta da ampla e complexa realidade brasileira.

Mesmo com os limites mencionados, indicou-se que, se o campo for considerado numa perspectiva mais ampla do que a oficial existente (IBGE/INEP), há uma rede significativa de escolas nele situadas. Contudo, elas não são vistas como escolas rurais ou do campo, nem pelos professores que nelas atuam, nem por dirigentes municipais de educação, nem pelas famílias dos estudantes e, muitas 
vezes, nem mesmo pelos sujeitos coletivos do campo - movimentos sociais e sindicais - que sustentam o Movimento de Educação do Campo.

O reconhecimento e a visibilidade dessas escolas como "escolas do campo" constituem, todavia, um primeiro e indispensável passo para que elas construam suas identidades de "escolas do campo" e funcionem como tal nos contextos de territórios rurais em que se inserem, protagonizando dinâmicas de desenvolvimento desses territórios em perspectiva de disputa de hegemonia. Ainda no âmbito da governança, caberá a iniciativa da elaboração de projetos político-pedagógicos próprios e apropriados a essa perspectiva identitária, ou seja, com desenhos de métodos e práticas curriculares, material didático etc., adequados aos princípios da educação do campo definidos nos termos do Decreto $\mathrm{n}^{0} 7.352$ (Brasil, 2010). E, um passo mais à frente nas lutas de hegemonia, caberá aos sujeitos do Movimento de Educação do Campo calcular suas estratégias e, zelando pelo seu projeto de desenvolvimento e de sociedade, forçar para que os sistemas oficiais cumpram tais preceitos no que concerne à função pedagógica e social da escola do campo.

\section{REFERÊNCIAS}

ABRAMOVAY, R. Funções e medidas da ruralidade no desenvolvimento contemporâneo. Rio de Janeiro: IPEA, 2000. (Textos para Discussão, n. 702).

ABRAMOVAY, R. Estratégias alternativas para a extensão rural e suas consequências para os processos de avaliação. 2007. Trabalho apresentado ao $45^{\circ}$ Congresso da Sociedade Brasileira de Economia, Administração e Sociologia Rural, Londrina, 2007. Disponível em: <http://ceragro.iica.int/Documents/Abramovay_Texto_ Avalia_o_ATER.pdf >. Acesso em: ago. 2011.

ANHAIA, E. M. Constituição do Movimento de Educação do Campo na luta por políticas de educação. 2010. 108 p. Dissertação (Mestrado Educação) - Universidade Federal de Santa Catarina, Florianópolis, SC, 2010.

BRASIL. Ministério do Desenvolvimento Agrário. Secretaria de Desenvolvimento Territorial. Orientações para a prática no apoio ao Desenvolvimento Sustentável de Territórios Rurais. Brasília, DF: SDT/MDA, 2004.

BRASIL. Lei $\mathrm{n}^{0}$ 11.326, de 24 de julho de 2006. Estabelece as diretrizes para a formulação da Política Nacional da Agricultura Familiar e Empreendimentos Familiares Rurais. Diário Oficial da União, Brasília, DF, 25 de jul. 2006. Disponível em: <http://www.planalto.gov.br/ccivil_03/_ato2004-2006/2006/lei/l11326.htm>. 
BRASIL. Decreto $\mathrm{n}^{0}$ 7.352, de 4 de novembro de 2010. Dispõe sobre a política de educação do campo e o Programa Nacional de Educação na Reforma Agrária - PRONERA. Diário Oficial da União, Brasília, DF, 5 nov. 2010. Disponível em: <http://www.planalto.gov.br/ccivil_03/_ ato2007-2010/2010/decreto/d7352.htm>.

CNEC. Conferência Nacional Por Uma Educação do Campo, 2., 2004. Luziânia. Declaração Final. Luziânia, GO: CNCE, ago. 2004.

FAVARETO, A.; ABRAMOVAY, R. Contrastes territoriais dos indicadores de renda, pobreza monetária e desigualdade no Brasil da década de 1990. Ruris, Campinas, SP, v. 4, n. 1, mar. 2010.

FERNANDES, B. M. Por uma educação básica no campo. In: FERNANDES, B. M; ARROYO, M. G. A educação básica e o movimento social do campo. Brasília, DF: Articulação Nacional por uma Educação Básica do Campo, 1999. (Coleção por uma Educação Básica do Campo, n. 2, p. 40-55).

FERnANDES, B. M. Sobre a Tipologia de Territórios. São Paulo: CAPES; CLACSO, 2008. Disponível em: <http://www.acciontierra.org/IMG/pdf/BERNARDO_ TIPOLOGIA_DE_TERRITORIOS.pdf $>$. Acesso em: ago. 2011.

FERNANDES, B. M; MOLINA, M. C. O Campo da Educação do Campo. In: MOLINA, M. C.; JESUS, S. M. S. A. (Org.). Contribuições para a construção de um projeto de Educação do Campo. Brasília, DF: Articulação Nacional Por uma Educação do Campo, 2004. (Coleção Por Uma Educação do Campo, $\mathrm{n}^{\circ} .5$ ).

MOLINA, M. C. A contribuição do Pronera na construção de políticas públicas de educação do campo e desenvolvimento sustentável. Brasília. 2003, 282 p. Tese (Doutorado em Desenvolvimento Sustentável) - Universidade de Brasília, Brasília, DF, 2003.

MUNARIM, A. Prefácio - Educação do Campo: desafios teóricos e práticos. In: MUNARIM, A. et al. Educação do Campo: reflexões e perspectivas. Florianópolis, SC: Insular, 2010. p. 9-18.

PERICO, R. E.; RIBEIRO, M. P. Ruralidade, territorialidade e desenvolvimento sustentável. Brasília, DF: MDA/SDT-IICA, 2005. 
ROCHA, M. R. T.; FILIPPI, E. E. Política para o desenvolvimento dos territórios rurais no Brasil: propostas e fundamentos. In: SEMINARIO INTERNACIONAL DE DESARROLLO RURAL, 6., 2007, Bogotá. Anales del VI Seminario Internacional de Desarrollo Rural.... Bogotá, 2007. Disponível em: <http://www.ufrgs.br/pgdr/ arquivos/494.pdf $>$. Acesso em: jul. 2012.

VEIGA, J. E. Cidades Imaginárias: o Brasil é menos urbano do que se calcula. Campinas, SP: Autores Associados, 2002.

VEIGA, J. E. A dimensão rural do Brasil. Estudos Sociedade e Agricultura, Rio de Janeiro, n. 22, p. 21-33, abr. 2004 .

UNESCO. Conferência Nacional por uma Educação Básica no Campo: desafios e propostas de ação. Luziânia, GO, jul. 1998a.

UNESCO. Conferência Nacional por uma Educação Básica no Campo: texto base. Luziânia, GO, jul. 1998b.

VERDE, V. V. Território, ruralidade e desenvolvimento. Curitiba, PR: Ipardes, maio 2004. (Primeira Versão, n. 1). 